\title{
Memorial lecture: viruses and the developing nervous system
}

\section{Marc Tardieu}

\author{
Address: Université Paris Sud 11, Neurologie pédiatrique et centre de référence maladies inflammatoires du cerveau, Hôpital Bicêtre Assistance \\ publique hôpitaux de Paris, Inserm U802, France \\ from Fifth Dominique Dormont International Conference. Mother-to-child transmitted viral diseases: from transmission to children care \\ Paris, France. 26-28 March 2009 \\ Published: 22 July 2009 \\ Retrovirology 2009, 6(SuppI I):LI0 doi:I0.I I86/I742-4690-6-SI-LI0
}

This abstract is available from: http://www.retrovirology.com/content/6/SI/LI0

(c) 2009 Tardieu; licensee BioMed Central Ltd.

The next Dominique Dormont International Conference will cover the consequences of viral infections on the developing nervous system, a subject usually not studied per se. The term of "developing nervous system" should be understood as the development of brain and spinal cord from the end of $1^{\text {st }}$ month post conception to the end of the $2^{\text {nd }}$ year of life. Such a complex subject will require a clinico-biological approach, evaluating the parallel development of immune and nervous systems and considering the variety of clinical situations resulting from virus-related insults to the developing nervous system. Several major events occur during the long interval of time we consider: first trimester of gestation: neural precursors proliferation and initial mesenchymatous/microglia invasion; second trimester: neural cell migration to constitute the cortical layers; last trimester: glial cell multiplication, dendritic network disposition and angiogenesis; first two years of life: oligodendrocytes/myelin maturation and blood-brain barrier constitution.

Clinical consequences of any insult to the developing nervous system will be highly dependent on time of the injury during development. For example, CMV infection occurring during the second trimester will induce abnormal cortical malformations (polymicrogyria or pachygyria), whereas HIV-1 transmission during last trimester does not result in brain malformation but in reduced brain size at birth.

Virus-induced insults are of multiple mechanisms. The most frequent ones are indirect insults either through modification of vessels or induced inflammation/ immune responses. Early occurring HIV-1 related encephalopathy is most likely the consequence of both virusrelated and immune-related toxic effect occurring during late pregnancy and initial weeks of life. Less studied, but an important field to be explored, are virus-induced disturbances of angiogenesis and of blood-brain barrier maturation. CMV, VZV, HIV infections can induce alterations of brain vessels, as does autoimmune disorders such as antiphospholipid syndromes. Finally, viruses may infect directly neuro-ectodermal cells and induce cytopathic effect and tissue necrosis. Herpes simplex infection of the brain, although observed at any age, is more frequent during the first two years of life. This is, at least in part, the consequence of genetic variations in the inflammatory and immune response to herpes simplex virus with a specific dependence of neural cells. Immunogenetic is another partner in this highly complicated interaction between developing brain, developing immune system and viruses. 